
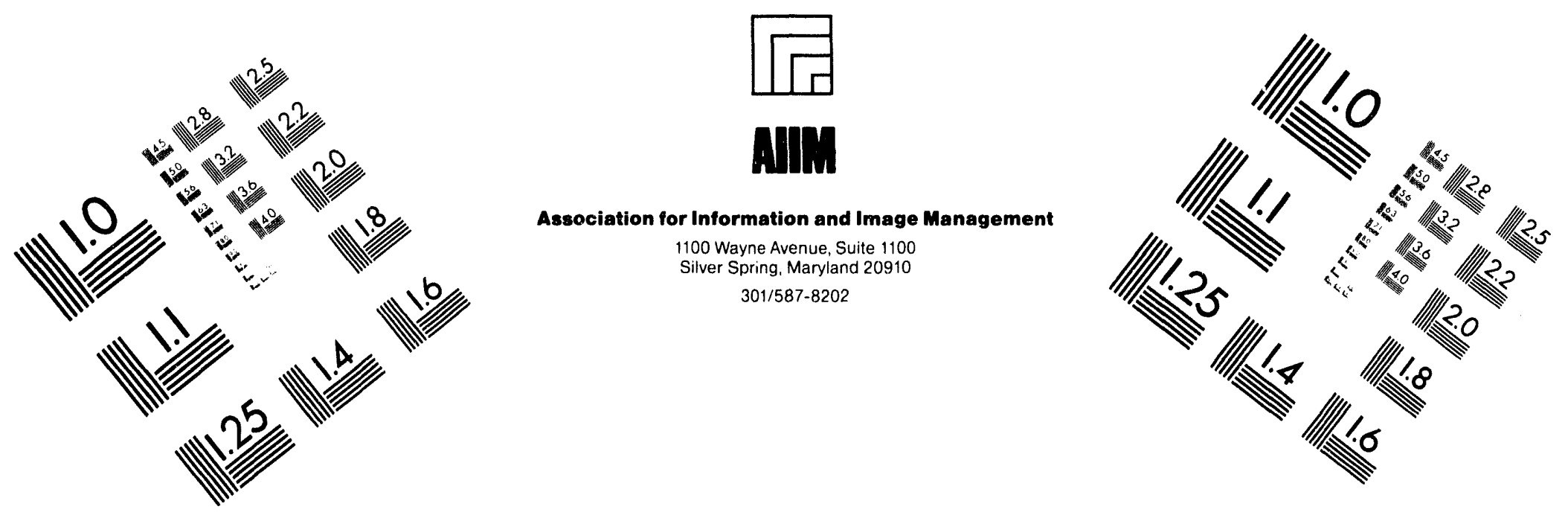

\title{
Centimeter
}

(15)

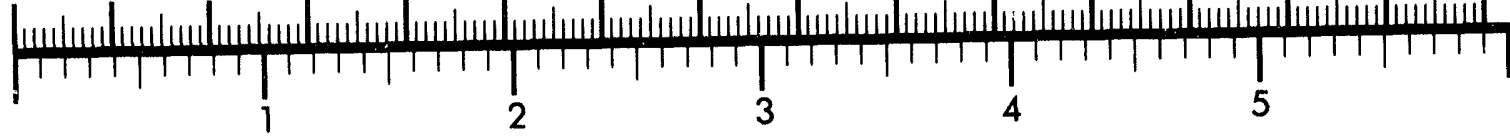
Inches
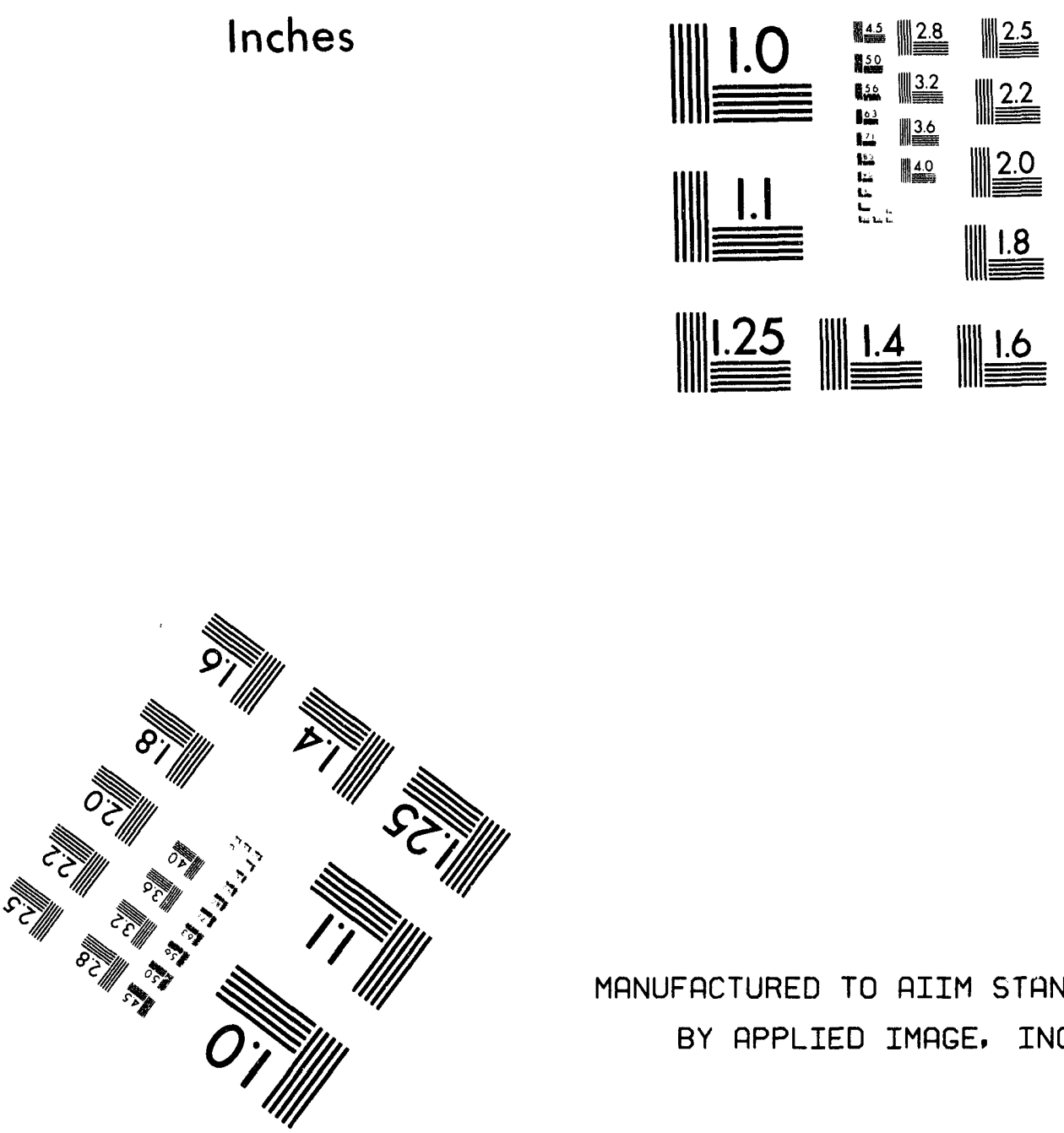

MANUFACTURED TO AIIM STANDARDS

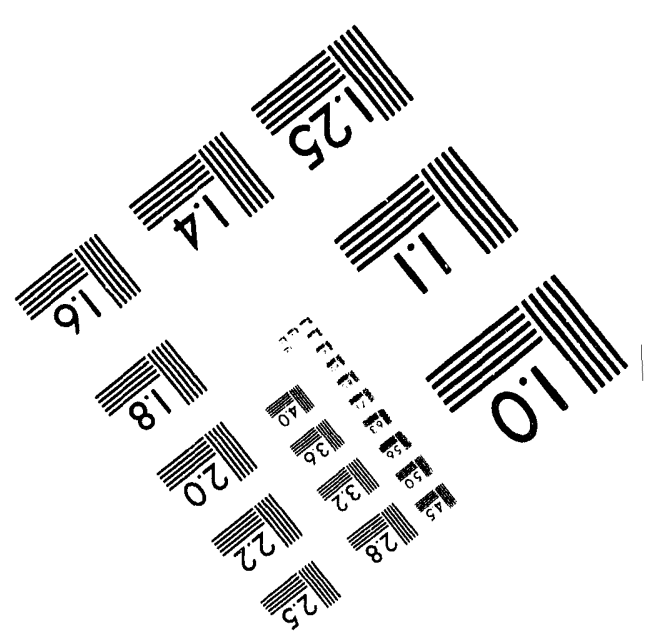



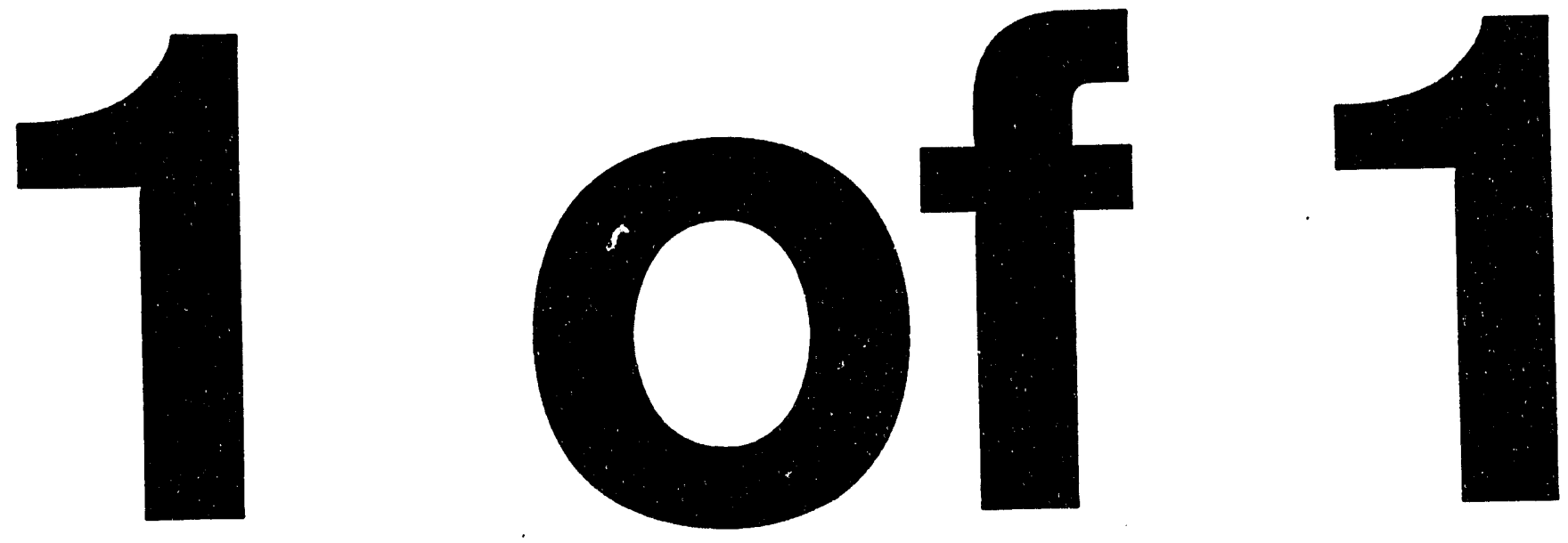
DOE/PC/93209-- T3

DEVELOPMENT OF A GAS-PROMOTED OIL AGGLOMERATION PROCESS

Technical Progress Report

April 1, 1994 - June 30, 1994

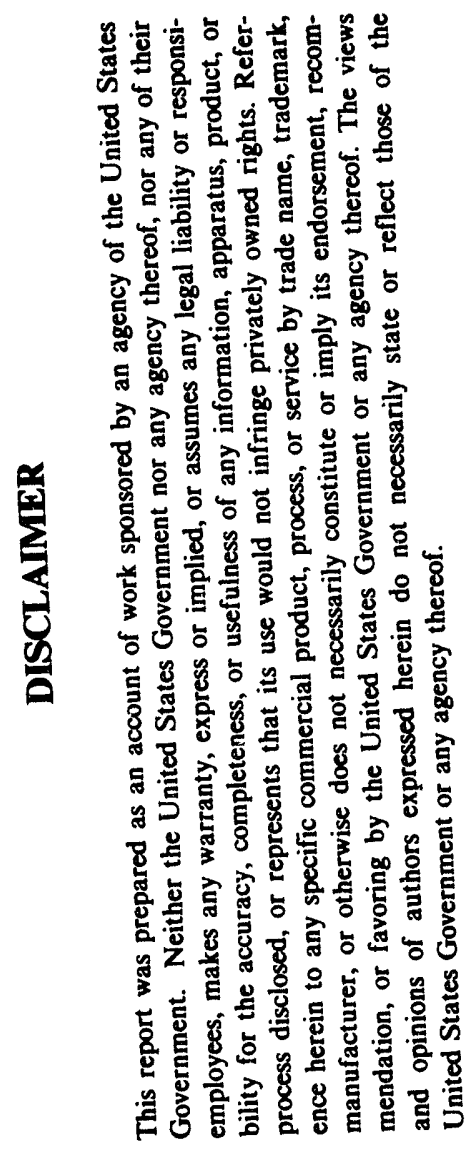

T. D. Wheelock

Principal lnvestigator

J. Drzymala

Postdoctoral Fellow

F. Zhang
Graduate Student

C. Nelson

Summer Intern

Chemical Engineering Department and

Iowa State Mining and Mineral Resources Research Institute

Iowa State University

Ames, Iowa 50011

DOE Grant No. DE-FG22-93PC93209

Report Prepared for

U.S. Department of Energy

Pittşurgh Energy Technology Center

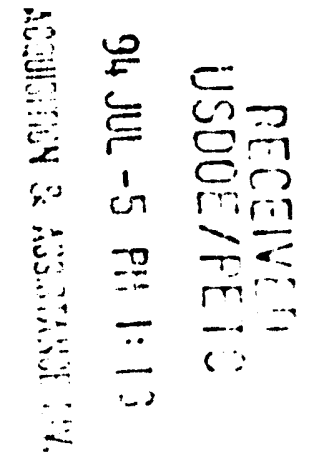

Pittsburgh, Pennsylvania 
DEVELOPMENT OF A GAS-PROMOTED OIL AGGLOMERATION PROCESS

Technical Progress Report

April 1, 1994 - June 30, 1994

T. D. Wheelock, Principal Investigator

\begin{abstract}
PURPOSE
The overall purpose of this research project is to carry out the preliminary laboratory-scale development of a gas-promoted, oil agglomeration process for cleaning coal using model mixing systems.
\end{abstract}

\title{
INTRODUCTION
}

The design and construction of a model mixing system for conducting oil agglomeration tests were reported previously as well as the results of a series of calibration and shakedown tests (refs. 1 and 2). The system consists of a flat bottom tank which is fitted with four vertical baffles, a cover, and a turbine agitator. The tank has an inside diameter of $15.24 \mathrm{~cm}(6.0 \mathrm{in}$.$) ,$ height of $15.24 \mathrm{~cm}(6.0 \mathrm{in}$.$) , and net volume of 2.87 \mathrm{~L}$. The tank is connected to a photometric dispersion analyzer so that the turbidity of a coal particle suspension undergoing agglomeration can be monitored.

Measuring the turbidity of a particle suspension requires application of the Beer-Lambert law (ref. 3). However, since this law applies for dilute suspensions, it is questionable whether or not it applies to the somewhat more concentrated coal suspensions required for the present project. Therefore, to determine the law's applicability, a series of turbidity measurements was 
conducted on particle suspensions which varied in particle concentration over a wide range, and the results were analyzed to see how well they agreed with the law.

To determine the effect of air in promoting the oil agglomeration of coal particles in an aqueous suspension, a number of agglomeration tests were conducted with the model mixing system. Finely ground Pittsburgh No. 8 coal was used for these tests, and the amount of air present was controlled carefully. The agglomeration process was monitored by observing the change in turbidity of the system.

\section{WORK PERFORMED}

\section{Applicability of the Beer-Lambert Law}

The applicability of the Beer-Lambert law for characterizing coal particle suspensions was verified by measuring the apparent turbidity of such suspensions with a photometric dispersion analyzer. Small particles of anthracite coal were suspended in water using the previously described mixing system (ref. 1). A small stream of material was conducted from the mixing system to the photometric dispersion analyzer and back to the mixing system. The light transmissiveness of the suspension was determined by measuring the intensity of a narrow beam of light which passed through the suspension as it flowed through a glass tube having an inside diameter of $3.0 \mathrm{~mm}$. Assuming the Beer-Lambert law to be applicable, the turbidity $\tau$ would be given by the following relation:

$$
\tau=\frac{1}{\mathrm{~L}} \ln \frac{\mathrm{V}_{\mathrm{o}}}{\mathrm{V}}
$$

where $L$ is the optical path length through the suspension (assumed to be $3.0 \mathrm{~mm}$ ), $V_{0}$ is the output signal voltage from the photometric dispersion analyzer when pure water is present in the 
measuring tube, and $V$ is the output signal voltage when a particle suspension is present. The design of the meastring system is such that the output signal is proportional to the intensity of the transmitted light. For a suspension of uniformly sized particles, the turbidity would be related to particle concentration as follows:

$$
\tau=\mathrm{NC}
$$

where $\mathrm{N}$ and $\mathrm{C}$ are the number concentration and scattering cross section, respectively, of the particles. For a spherical particle, its scattering cross-section would be given by the expression,

$$
C=\frac{1}{4} Q \pi d^{2}
$$

where $Q$ is a non-dimensional scattering coefficient for the particle of diameter $d$. For particles which are much larger than the wavelength of light, the scattering coefficient is equal to 2 (ref. 4). By combining the last two equations, the following relation is obtained:

$$
\tau=\frac{1}{2} \pi \mathrm{d}^{2} \mathrm{~N}
$$

It can be shown that if the particle size of a suspension of monosize, spherical particles is varied while holding the total mass of particles and system volume constant, the turbidity of the suspension will vary with particle size and with particle concentration as indicated below.

$$
\begin{aligned}
& \tau=\mathrm{k}_{1} \mathrm{~d}^{-1} \\
& \tau=\mathrm{k}_{2} \mathrm{~N}^{1 / 3}
\end{aligned}
$$

In other words, the turbidity will vary inversely with particle size or directly with number concentration to the one-third power. 
The applicability of equations 4,5 , and 6 for monosize, coal particle suspension was verified by conducting a series of measurements on suspension of closely-sized anthracite particles. Anthracite lumps were crushed and ground in the dry state, and the ground material was subsequently separated into a series of size fractions by dry screening using sieves which ranged from 100 to 400 mesh. The material retained on each screen was subsequently washed on the screen with water to remove fines.

To prepare a suspension for the turbidity measurement, $5.0 \mathrm{~g}$ of particles of a given size was mixed with deionized water. The suspension was degassed at room temperature by apply a vacuum equivalent to an absolute pressure of $13 \mathrm{kPa}$ over a period of $30 \mathrm{~min}$. The suspension was stirred during this operation. After degassing, the suspension was transferred to the previously described $2.87 \mathrm{~L}$ mixing system fitted with a $5.0 \mathrm{~cm}$ diameter turbine impeller. After removing all of the air from the system, the suspension was conditioned by stirring the suspension for $2 \mathrm{~min}$. at $1000 \mathrm{rpm}$. During this time, a stream of material was circulated through the turbidity measuring tube, and at the end of the conditioning period a measurement of the turbidity was made. The mixing system was then emptied and prepared for the next measurement.

For the first series of measurements, the number concentration of particles was kept constant $(\mathrm{N}=7150 \mathrm{particles} / \mathrm{ml})$ while the average particle size was varied over the range from 40.5 to $137 \mu \mathrm{m}$. To keep $\mathrm{N}$ constant, the corresponding mass of coal had to vary from $1.06 \mathrm{~g}$ for the smallest particle size to $40.89 \mathrm{~g}$ for the largest size. The results presented in Figure 1 indicate that the turbidity of the suspensions varied directly as the square of particle diameter based on screen opening size. This result was in general agreement with equation 4 . However, since the 


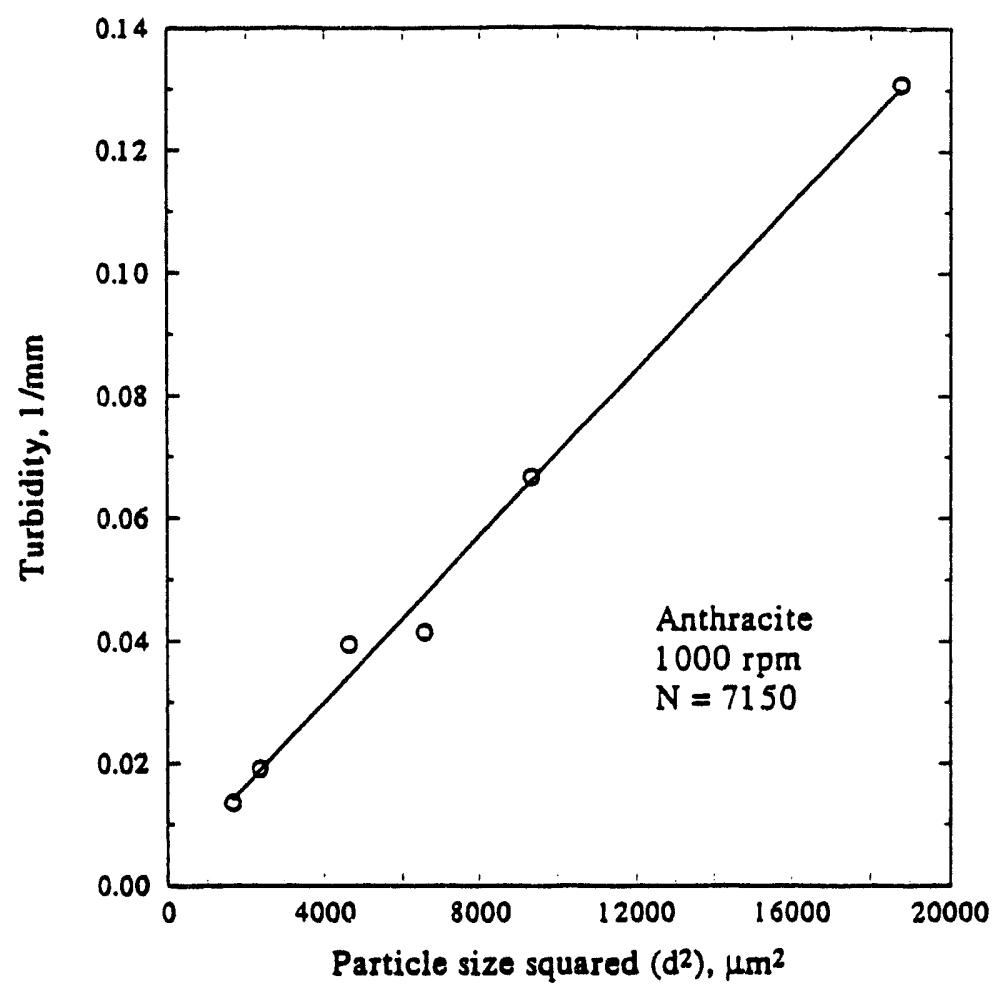

Figure 1. Effect of paricle size on the turbidity of anthracite coal suspensions having the same particle concentration (7150 particles/ml).

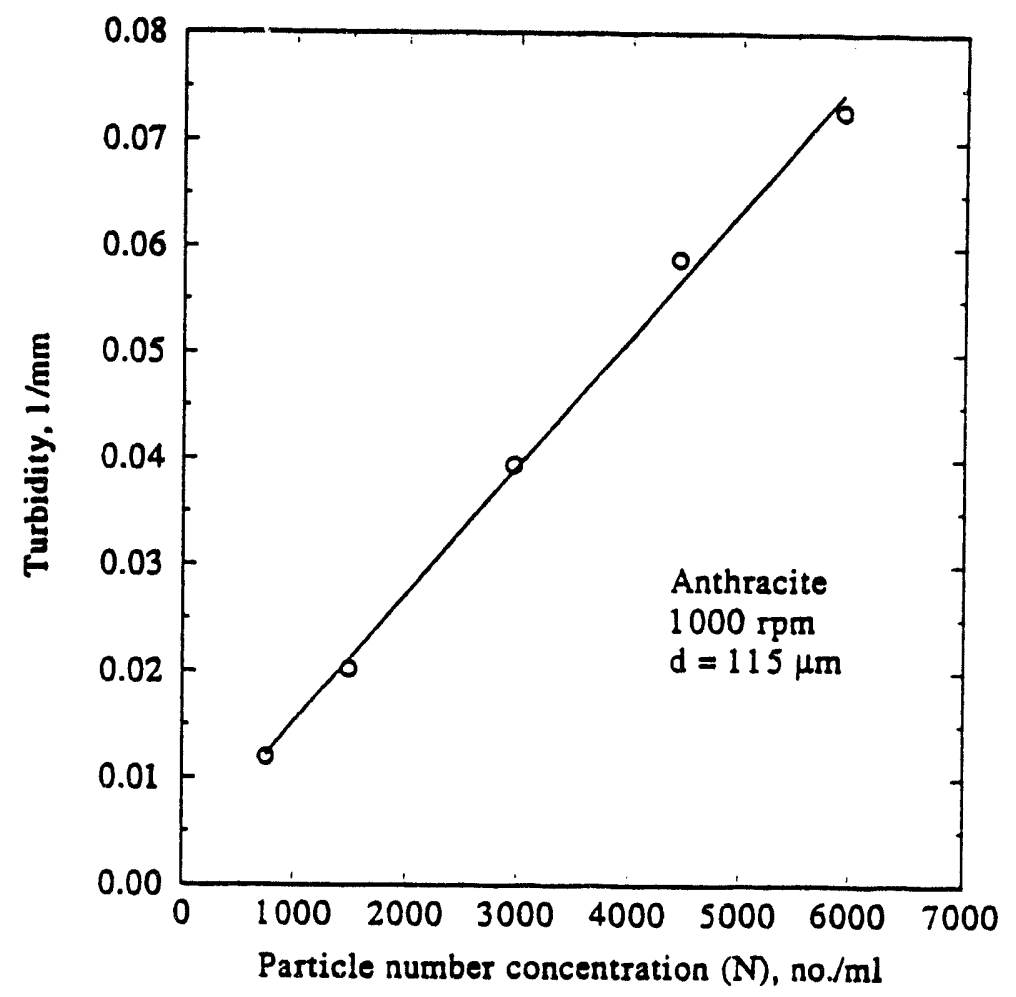

Figure 2. Effect of particle concentration on the turbidity of anthracite coal suspensions prepared with uniformly sized particles. 
line fitted to the data by linear regression did not pass through the origin, the results suggest that the surface of the measuring tube may not have been absolutely clean or may have become coated when the particle suspension was flowing through it.

For the second series of measurements the particle size was held constant $(d=115 \mu \mathrm{m})$ while the particle concentration was varied over a range from 739 to 5913 particles $/ \mathrm{ml}$. The total mass of paricles had to increase from $2.50 \mathrm{~g}$ at the lowest particle concentration to $20.0 \mathrm{~g}$ at the highest particle concentration. To calculate the particle concentration, it was assumed that the particles were spherical and that the density $\rho$ of an individual particle was $1.48 \mathrm{~g} / \mathrm{cm}^{3}$. Therefore, the particle concentration $\mathrm{N}$ was given by the following expression:

$$
N=\frac{6 M}{\pi \rho d^{3} V}
$$

where $M$ is the total mass of particles and $V$ is the volume of the suspension. The results presented in Figure 2 show the turbidity varied directly with particle concentration as predicted by equation 4 . However, again the line fitted by linear regression did not pass through the origin suggesting a clouding of the measurement tube.

For the third series of measurements, the total mass of particles was held constant at $5.0 \mathrm{~g}$ and the particle size was varied over the range from 40.5 to $137 \mu \mathrm{m}$. Since the total volume of the suspension was held constant at $2.87 \mathrm{~L}$, the particle concentration had to vary from 874 particles $/ \mathrm{ml}$ for the largest particles to 33,840 particles $/ \mathrm{ml}$ for the smallest particles. The results which are presented in Figures 3 and 4 show that the turbidity varied directly with $\mathrm{d}^{-1}$ as predicted by equation 5 or directly with $\mathrm{N}^{1 / 3}$ as predicted by equation 6 . 


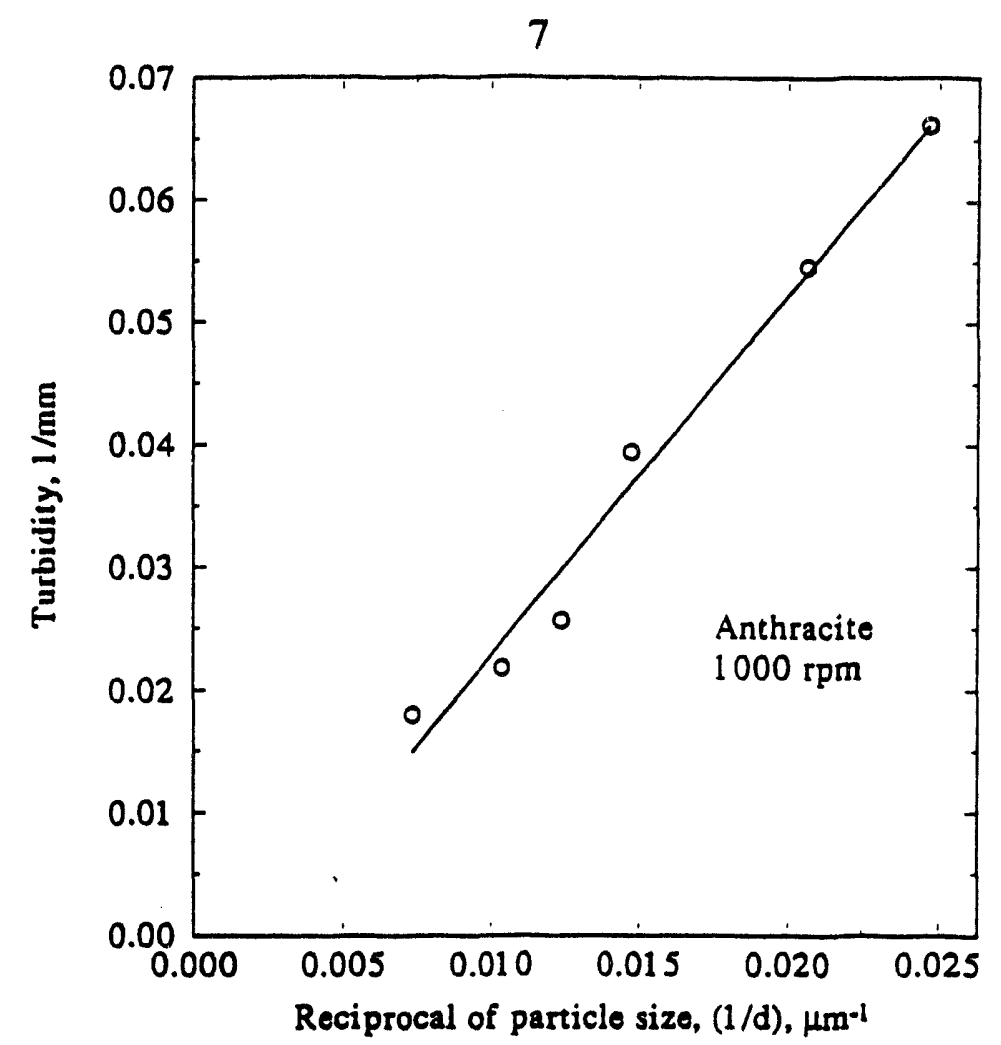

Figure 3. Correlation between turbidity and particle size for anthracite coal suspensions containing $5.0 \mathrm{~g}$ of solids.

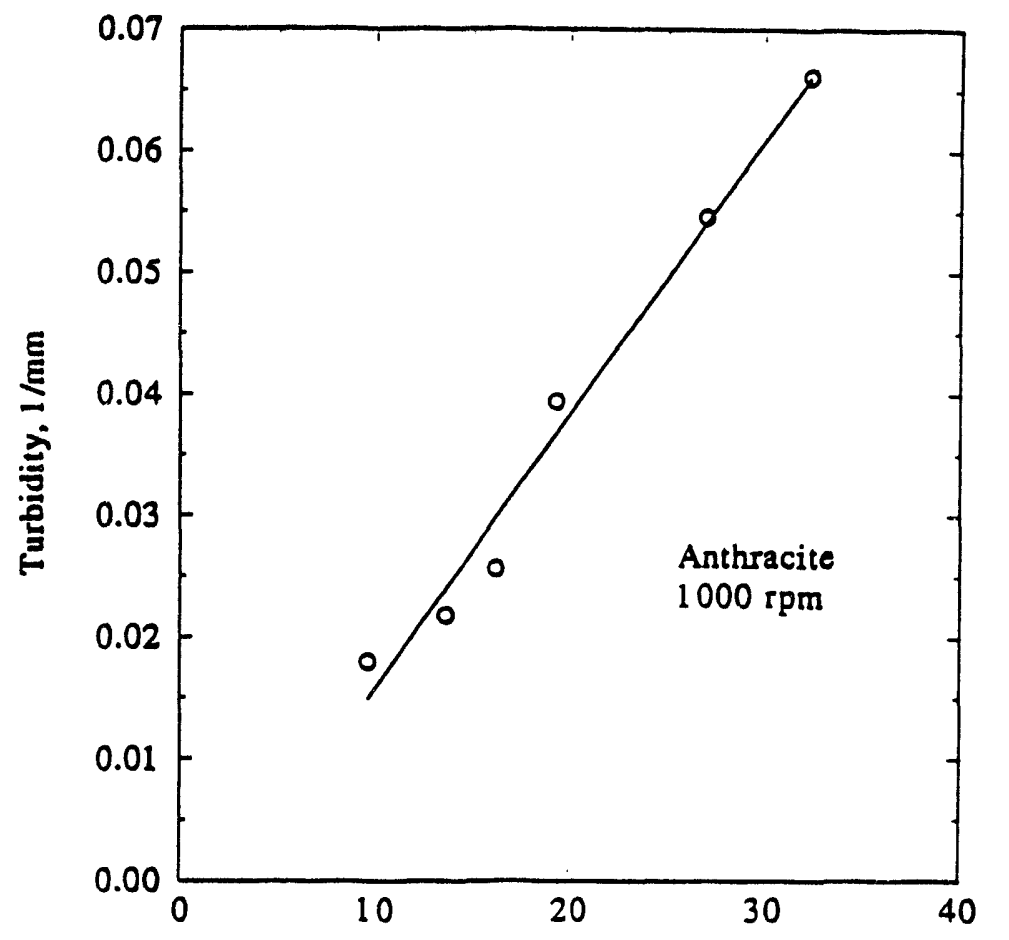

Cube root of particle number concentration $\left(\mathrm{N}^{1 / 3}\right)$, $(\mathrm{no} / \mathrm{ml})^{1 / 3}$

Figure 4. Correlation between turbidity and particle concentration for anthracite coal suspensions containing $5.0 \mathrm{~g}$ of solids. 
The implication of the preceding results is that a particle agglomeration process can be monitored by observing the change in the turbidity of a particle suspension as it undergoes agglomeration at least for solids concentrations up to $1.4 \%$. In a batch process a given mass of particles is agglomerated to form larger particles. As the agglomerates increase in size, the total number of particles decreases so the turbidity will decrease. By the end of the process the larger particles or agglomerates are composed of many smaller particles. Since there will always be some void space between the constituent particles of an agglomerate, equations 5 and 6 have to be modified by introducing the porosity $\epsilon$ of an agglomerate in order to have the equations apply to an agglomeration process. For a process in which small monosize particles are converted into large monosize agglomerates the turbidity would vary in accordance with the following expressions:

$$
\begin{aligned}
& \tau=k_{1} d^{-1(1-\epsilon)} \\
& \tau=k_{2} N^{1 / 3(1-e)}
\end{aligned}
$$

Further modification of the preceding equations is required for them to represent the more general case involving a distribution of particle sizes.

\section{Oil Agglomeration of Pittsburgh No. 8 Coal}

A number of oil agglomeration experiments were conducted to determine how much air was required to promote the agglomeration of Pittsburgh No. 8 coal. The dried coal had an ash content of 27.8\%. The coal was crushed with a jaw crusher and roll mill, and the material was then divided into small portions by riffling. The small portions were stored under Argon until needed. Shortly before being used, an individual portion was reground with a roll mill to pass a No. 14 U.S. Standard screen. The material was ground further in a stirred ball mill so that 
more than $90 \%$ was finer than $37 \mu \mathrm{m}$. The ball mill charge consisted of $250 \mathrm{~g}$ coal, $250 \mathrm{~g}$ water, and $1200 \mathrm{~g}$ stainless steel balls (1/8 in. diameter). The mill was operated for 20 min. The product was partially dewatered with a Büchner filter funnel and then stored as a paste containing $56 \%$ solids in a refrigerator set at $5^{\circ} \mathrm{C}$.

The agglomeration experiments were conducted with the previously described $2.87 \mathrm{~L}$ mixing system fitted with a $5.0 \mathrm{~cm}$ diameter turbine impeller (ref. 1). Before conducting a typical agglomeration experiment the mixing system was partly filled with deionized water, and a measured quantity of coal paste was added and dispersed in the water. For some experiments the water was degassed before adding the coal, and for other experiments the mixture of water and coal was degassed. For still other experiments the system was not degassed. The most frequently used method of degassing involved applying a partial vacuum to the partly filled mixing system at room temperature. The partial vacuum corresponded to an absolute pressure of 5-6 kPa, and it was applied for about $20 \mathrm{~min}$. Afterwards the mixing system was topped off with degassed water. Any remaining gas bubbles were removed from the system.

To conduct an agglomeration experiment the coal suspension was first stirred at a given speed for $3 \mathrm{~min}$, and then a measured quantity of an agglomerant such as heptane was introduced in a single dose with a syringe. The progress of agglomeration was monitored by observing the change in turbidity of the suspension. This was accomplished by circulating a small stream of the suspension through the optical cell or measuring tube of a photometric dispersion analyzer. As the particles combined to form agglomerates the particle concentration decreased which reduced the turbidity of the suspension. The reduction in turbidity was reflected by an increase in the output signal from the photometric dispersion analyzer. 
Therefore, by plotting the output signal against mixing time it was possible to observe both the apparent rate of agglomeration and the extent of agglomeration.

The most remarkable result of this series of experiments was the discovery that even a small amount of air can promote the agglomeration of Pittsburgh No. 8 coal. Apparently even the air which is dissolved in water in equilibrium with the atmosphere at room temperature and pressure is sufficient to affect the agglomeration process. Under equilibrium conditions the water in which the coal particles were suspended could dissolve up to $57 \mathrm{ml}$ of air at room temperature and pressure.

To determine the effect of different amounts of air on the agglomeration process, several tests were conducted in which a small amount of air was added to the agglomeration system after it had been prepared with water which had been degassed by applying a vacuum as described above before coal was introduced. For each test a suspension containing $1 \mathrm{w} / \mathrm{v} \%$ solids was stirred at $1500 \mathrm{rpm}$, and heptane was added at a level of $0.2 \mathrm{ml} / \mathrm{g}$ coal or $20 \mathrm{v} / \mathrm{w} \%$. The results presented in Figure 5 indicate that when no air was added to the mixing system, the output signal from the photometric dispersion analyzer remained flat for up to $2 \mathrm{hr}$ showing that no agglomeration occurred. However, when only $7 \mathrm{ml}$ of air was added 9 min after heptane was introduced, the output signal immediately started to rise and continued to rise steadily showing that agglomeration took place. The addition of larger amounts of air produced even larger and more rapid increases in the output signal indicating higher rates of agglomeration. Interestingly, when an experiment was conducted by agglomerating coal in water which had not been degassed, the results, which are also reported in Figure 5, were similar to those achieved when $7 \mathrm{ml}$ air was added to the degassed system. Therefore, it appeared that air dissolved in 


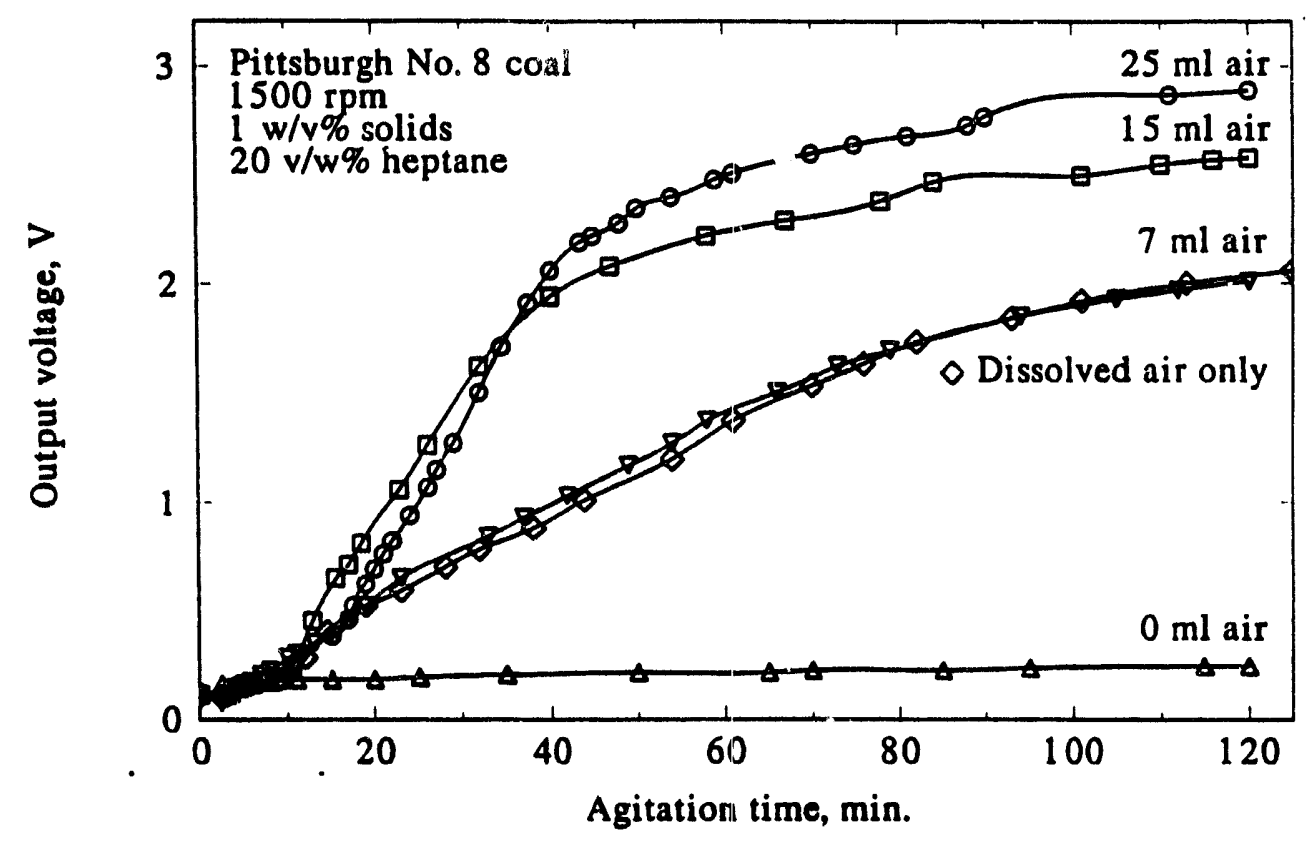

Figure 5. Results of agglomeration tests with Pittsburgh coal suspended in water which had been degassed followed by the introduction of different amounts of air.

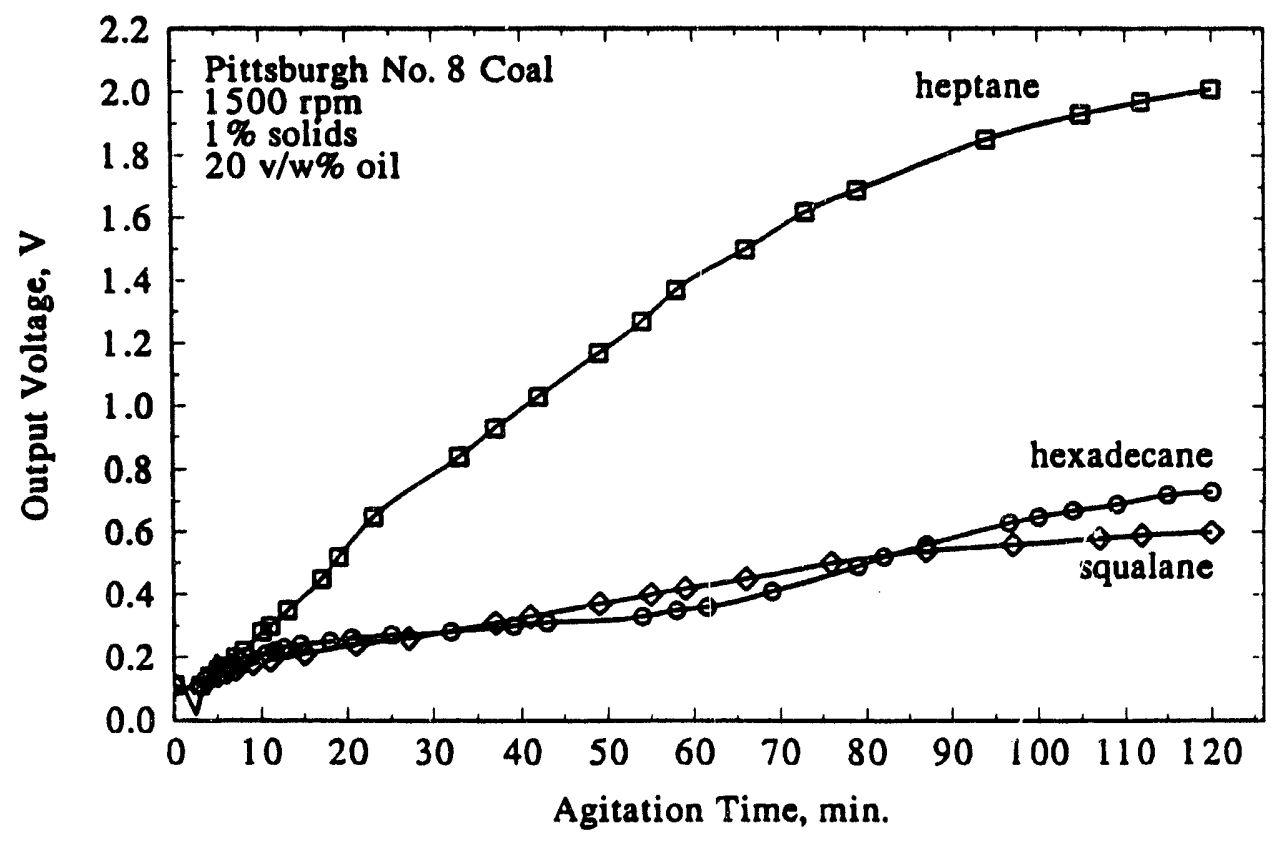

Figure 6. Results of agglomeration tests with Pittsburgh coal suspended in water which had not been degassed. 
the water was sufficient to promote agglomeration. But did the air have to come out of solution to promote agglomeration?

To answer this question additional experiments were conducted using water which had r.ot been degassed and hexadecane and squalane as agglomerants. No air was added to the system other than the air dissolved in the water. The results achieved with the different agglomerants and shown in Figure 6 indicate that the rate of agglomeration with either hexadecane or squalane was much smaller than with heptane. Although the solubility of heptane in water is small, it is still appreciably greater than that of hexadecane or squalane. The results suggest that when heptane is used as an agglomerant some heptane dissolves in the water and displaces enough air from the water to promote agglomeration. Hexadecane and squalane being much less soluble displace less air, and, therefore, have much less effect. This hypothesis was tested further by first saturating water with heptane and then using the water to suspend coal for a test of agglomeration. The water was not degassed otherwise and any excess heptane was removed by evaporation at room temperature before conducting the agglomeration test. The results of the agglomeration test which are reported in Figure 7 show that virtually no agglomeration took place during the first $35 \mathrm{~min}$, and then agglomeration proceeded very slowly. The results were in sharp contrast to those observed when an agglomeration test was conducted using water which had not been degassed. Also the results obtained with heptane saturated water were very similar to those observed with water which had been degassed by applying a partial vacuum. Therefore, it seems very likely that the displacement of air from water by heptane is sufficient to promote the agglomeration of Pittsburgh No. 8 coal. 


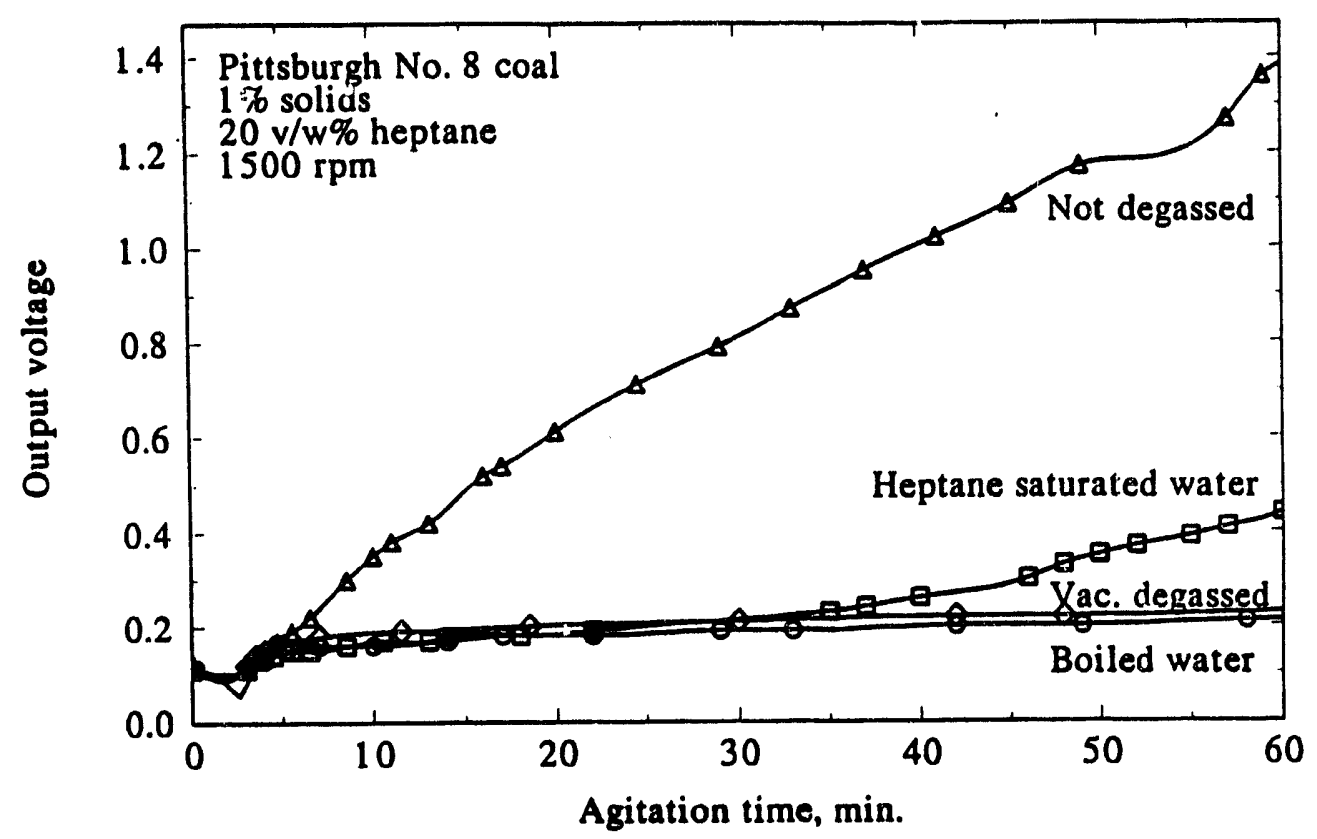

Figure 7. Results of agglomeration tests with Pittsburgh coal suspended in water which had received different treatments.

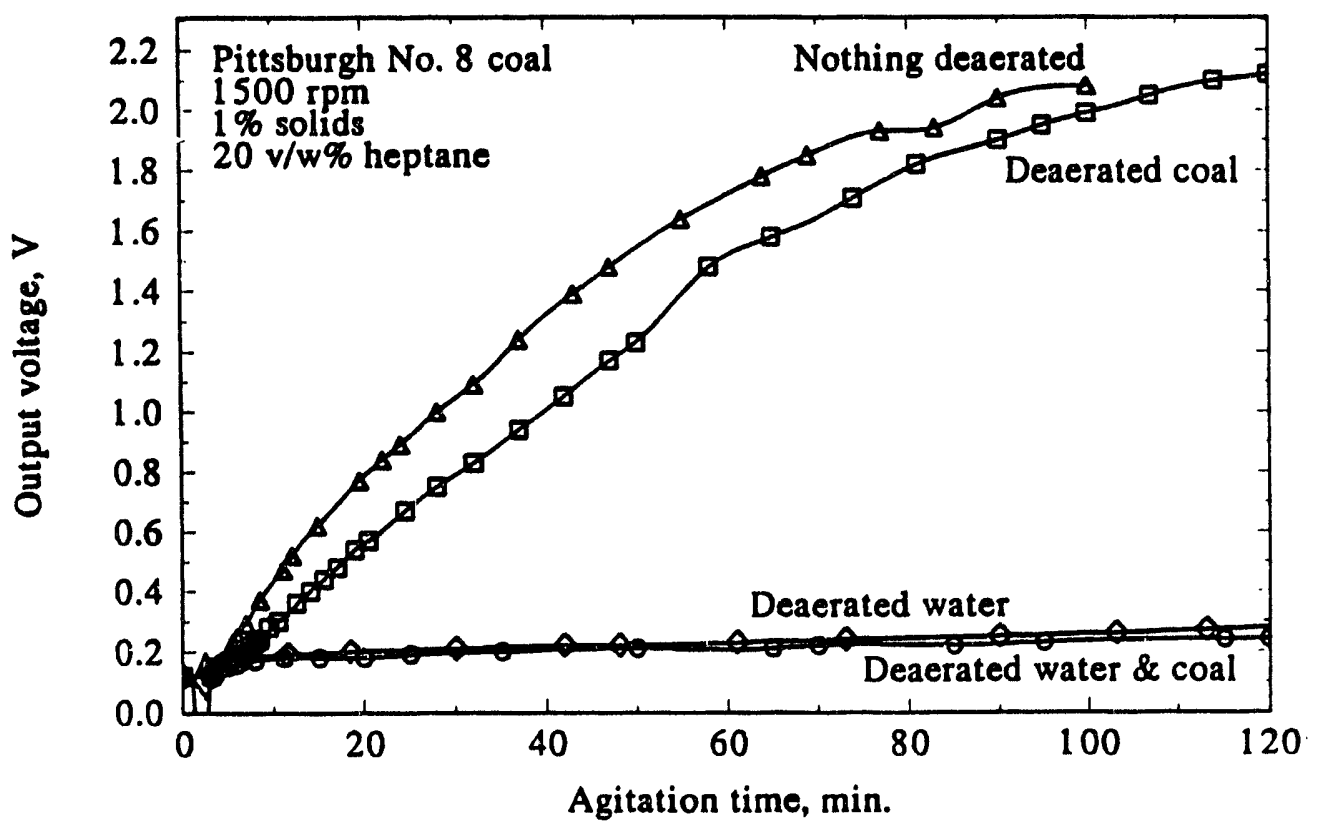

Figure 8. Results of agglomeration tests with Pittsburgh coal in suspensions prepared by different methods. 
Another method of degassing water used for agglomeration was also tested. This method involved boiling the water for 30 min to remove dissolved air. The water was then cooled rather quickly and used immediately for an agglomeration test. The results of this test which are shown in Figure 7 were almost identical to the results which had been obiained by vacuum degassing.

To complete the picture on the effects of deaeration, swo additional experiments were conducted. For one of these experiments the coal and water were first mixed together and then the suspension was deaerated by applying a partial vacuum as described above. The results which are shown in Figure 8 were almost identical to those obtained in an earlier but similar experiment in which only the water had been degassed. Therefore, it appeared that any air introduced by the coal paste in the earlier experiment was negligible. For another experiment the coal paste amounting to $52.5 \mathrm{~g}$ was first mixed with $100 \mathrm{ml}$ of water. This mixture was degassed by applying a partial vacuum. Water which had not been degassed was added to the mixture and an agglomeration test was conducted. The results reported in Figure 8 were similar to those obtained previously in which neither the water nor the coal paste were degassed. Therefore, these experiments indicate that any air introduced by the coal paste was negligible.

\section{PLANS FOR NEXT OUARTER}

The study of the effects of gas concentration in combination with other parameters on the agglomeration process will be continued. Other parameters will include particle concentration, agitator speed, agglomerant dosage, and type of coal. Most of the work to date has been with Pittsburgh No. 8 coal which is only moderately hydrophobic. In the future the work will be 
extended to a more hydrophobic material such as Upper Freeport coal. Also much larger particle concentrations will be used for some experiments.

\section{LITERATURE CITED}

1. T. D. Wheelock, "Development of a Gas-Promoted, Oil Agglomeration Process," Technical Progress Report for Sept. 1, 1993 - Nov. 30, 1993, Iowa State Mining and Mineral Resources Research Institute, Iowa State University, Ames, Iowa.

2. T. D. Wheelock, J. Drzymala, and F. Zhang, "Development of a Gas-Promoted, Oil Agglomeration Process," Technical Progress Report for Dec. 1, 1993 - Feb. 28, 1994, Iowa State Mining and Mineral Resources Research Institute, Iowa State University, Ames, Iowa.

3. J. Gregory and D. W. Nelson, Colloids and Surfaces, 18, 175-188 (1986).

4. J. Gregory, J. Colloid and Interface Science, 105, (no. 2), 357-371 (1985). 

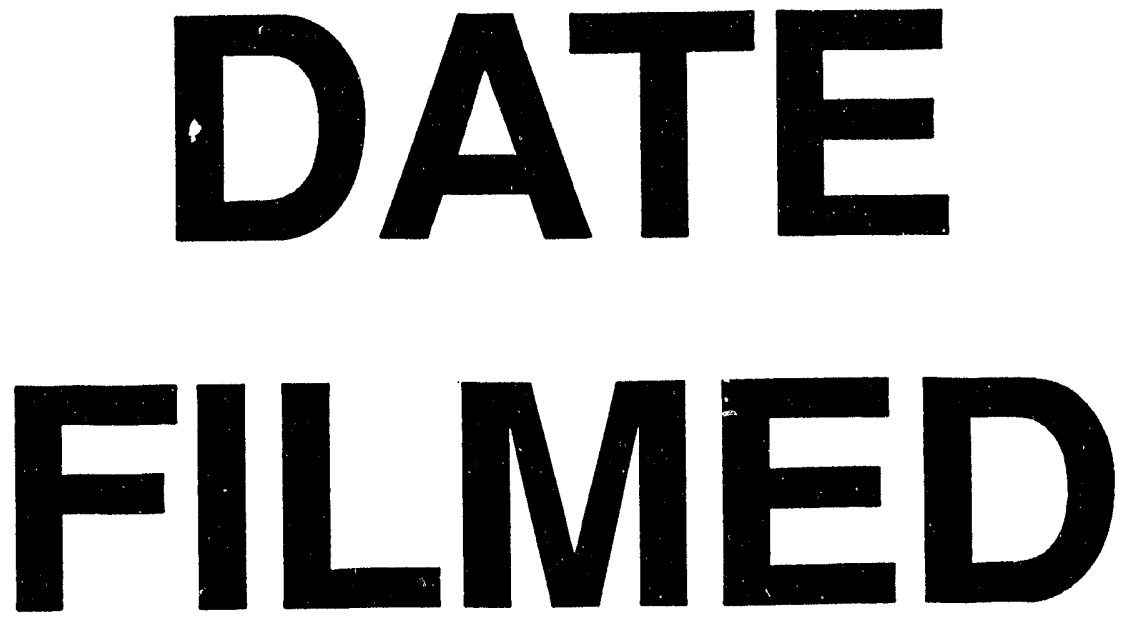

$10 / 17 / 94$
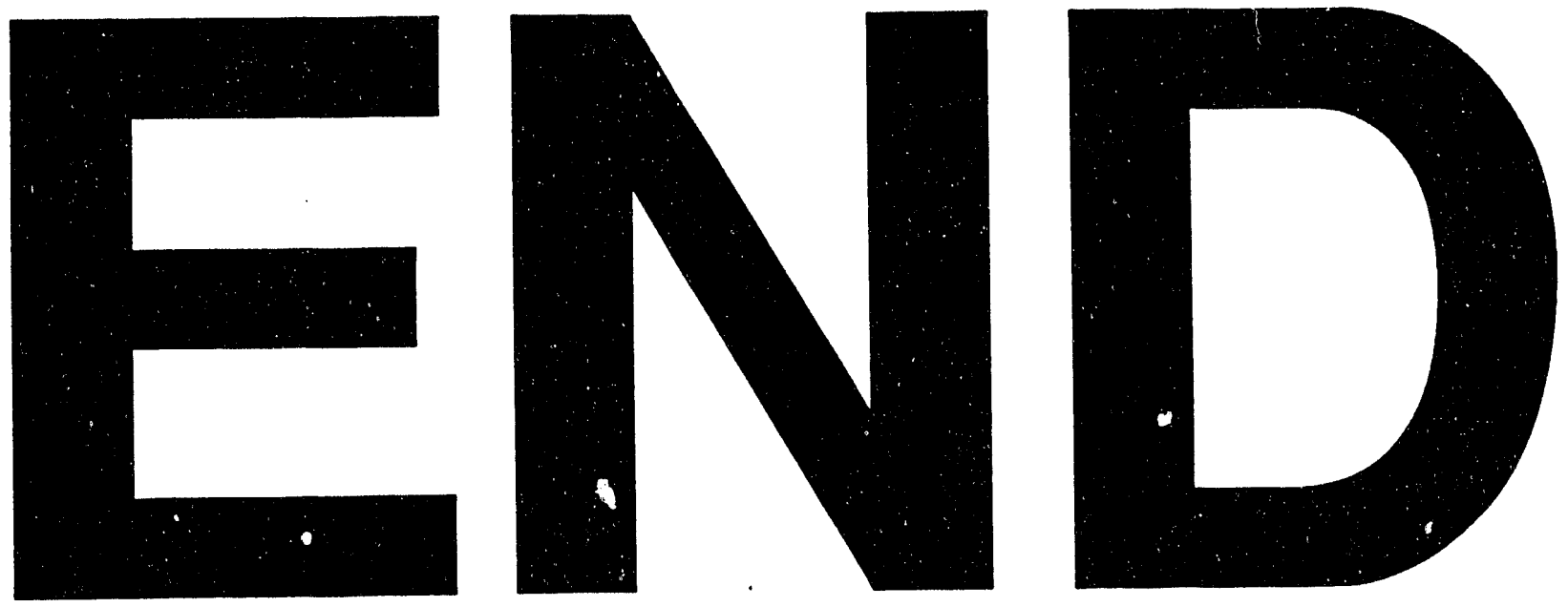


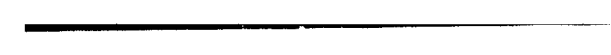

